\title{
The Research on Application of Business Intelligence in Mobile E-commerce
}

\author{
Lixin Gan \\ Jiangxi Science \& Technology Normal University \\ Nanchang, China \\ spiderganxin@163.com
}

\author{
Wei Tu \\ Jiangxi Science \& Technology Normal University \\ Nanchang, China \\ ncsytuwei@163.com
}

\author{
An Wang \\ Jiangxi Science \& Technology Normal University \\ Nanchang, China \\ wanganwangmenghua@163.com
}

\begin{abstract}
Mobile e-commerce (m-commerce) is not only the application of the superimposed E-commerce by mobile terminal. Characterized by flexibility, simplicity and convenience, it is popular with the consumers and brings new development opportunities for e-commerce enterprises. In order to solve the problems that the low personalized customer service are provided by M-commerce market, the paper put forward that business intelligence should be brought into the enterprise information construction. Through the use of business intelligence, the users can be fractionized, the comprehensive value of the users can be quantified all-around, marketing strategies and daily management of enterprises can be improved, which will provide decision support and regular research to improve core competitiveness of E-commerce enterprises.
\end{abstract}

Keywords-Mobile E-commerce; business intelligence; decision-making;

\section{INTRODUCTION}

With the continuous development of mobile communication and internet technology, especially the popularity of the intelligent mobile phone and the opening of $3 \mathrm{G}$ Internet, the scale of mobile internet users is growing at a unprecedented rate. According to the data of the Chinese Ministry and information industry, as to November in 2011, the users of mobile phone reached $975,335,000$, in which the users of $3 \mathrm{G}$ reached 118,732,000. Compared with the traditional internet, it has broader market prospect. Containing the mobile phone payment, mobile music, location service, phone games, social network, micro-blog, the application of colorful mobile internet are gradually penetrating into people's work, study, life and other fields. The rapid development of mobile internet laid a solid foundation for the M-commerce. At present, M-commerce has become a popular field instead of E-commerce, and the market of M-commerce is developing rapidly.

\section{THE INTRODUCTION TO MOBILE E-COMMERCE}

Derived from the concept of E-commerce, M-commerce refers to $\mathrm{B} 2 \mathrm{~B}, \mathrm{~B} 2 \mathrm{C} \mathrm{C} 2 \mathrm{C}$ E-commerce that use mobile phone,
PDA, tablet PC and other wireless terminal. Compared with traditional E-commerce based on computer platform (desktop PC, notebook computer), M-commerce has more extensive user base. Through the M-commerce platform, users can use smart phone or PDA to search, select and purchase good and service, get service, information and entertainment whenever and wherever. M-commerce enterprises can make and provide personalized service and information according to personalized demand and preference of consumers. The structure of M-commerce is shown in figure 1.

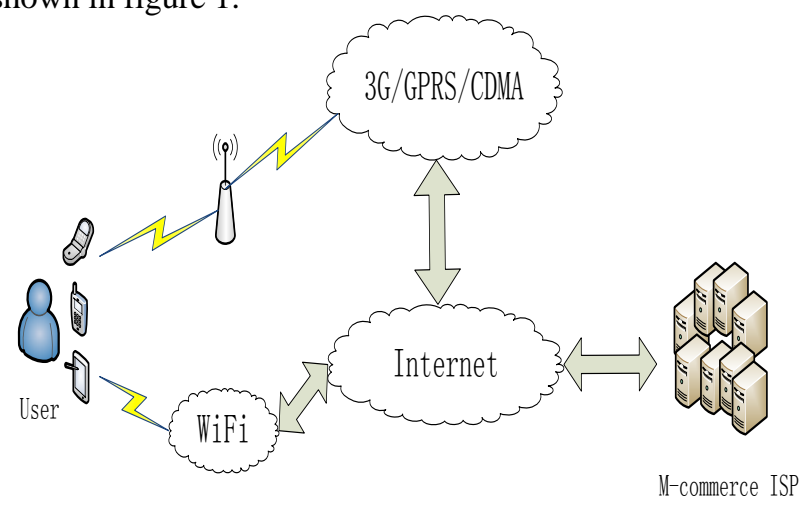

Figure 1. System Structure of M-commerce

At present, service provided by M-commerce enterprise on mobile network is rather rich. M-commerce service chart is shown in figure 2 . 


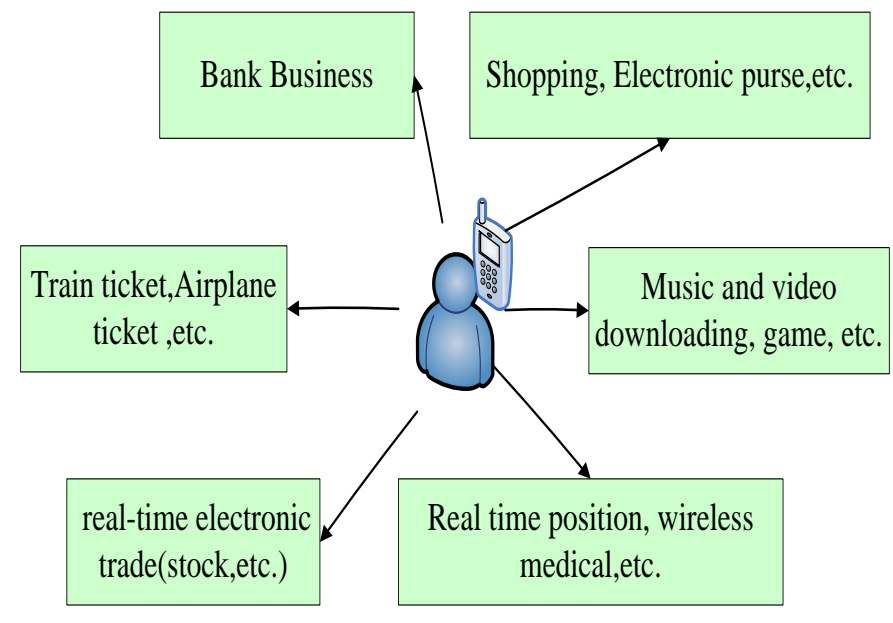

Figure 2. M-commerce Service Chart

While developing rapidly, M-commerce still has some problems. Such as, current and historical data, structural and non-structural data are difficult to integrate, islanding phenomenon exists; customer personal service is low; Mcommerce enterprises can't make real-time decision when facing massive data, automation and management level of production process need to be improved.

\section{THE INTRODUCTION TO BUSINESS INTELLIGENCE}

\section{A. The Concept of Business Intelligence}

Business intelligence (BI), proposed by Howard Dresner in 1989, is a kind of intelligence and ability, with which enterprises can use modern information technology to collect, manage and analyze structured and unstructured business data and information, create and accumulate business knowledge and opinions, improve decision-making lever, adopt efficient business operations, improve business process and all aspects of business performance, and enhance comprehensive competitiveness. BI aims to support better business decision-making. $[1,2]$

The emergence of $\mathrm{BI}$ is a process of gradual evolution and evolutionary, which experienced transaction processing system ( TPS ), engineering information system ( EIS ), management information system ( MIS ), decision supporting system stage, etc.

\section{B. The Main supporting Technology of BI}

BI mainly covers the Data Warehouse (DW), On-Line Analysis processing (OLAP), Data Mining (DM), Visualization Technology, Intelligence Retrieval, Knowledge Management, Personalized Recommendation Technology, Metadata, etc. [2,3]

The database is a data set which is subject-oriented, integrated, non-volatile and reflects time variant. It is used to support the management decision making [4]. The database mainly research and solve how to get information from database, and integrate, process and analysis business data in enterprise interior. It is the basis of data to realize $\mathrm{BI}$, and accurate summary to long-term transaction data in the enterprises.

1) OLAP, related to database closely, can analyze a large amount of business data online to generate new business information. What's more, it can monitor the effect of business operation in real-time to make sure users can freely connect with business data.

2) Data Mining(DM) is a process of decision-support. It means that use AL, genetic algorithms, machine learning, statistics, neural network, decision tree, clustering technology and other technology to discovery interesting knowledge from large amount of data existing in database, data warehouse and other information library. Then make inductive deduction, predict behavior of customers and help enterprise decision-makers to adjust marketing strategy to reduce the risk.[5,6]

3) Visualization Technology, refer to that can make the parsed data displayed in front of users intuitively and briefly by mean of graphics, image, virtual reality and so on.[2,7]

4) Intelligence Retrieval sorts the retrieval results to provide higher retrieval efficiency on basis of correlation of word document and word retrieval.

5) Knowledge Management, constantly update knowledge system to realize that make use of wisdom of all to enhance the ability of emergency and innovation of enterprises, through the construction of a quantitative and qualitative knowledge system, and the process of creating, sharing, integrating, recording, accessing, updating and innovating.

6) Personalized Recommendation Technology, a key technology of personalized service, provides users with information resource that they have interest in initiatively according to personalized information of users. [8,9]

7) Metadata, refers to relevant key data, such as data source definition, goal definition, transformation rules, which generates from the process of data warehouse construction.

BI can integrate structured and unstructured data, current and historical data which enterprises possess, use intelligent semantic to analyze, and then tap the potential useful information through online analysis and data analysis methods to provide decision-making basis of the operation for enterprise decision makers.

\section{THE SOLUTION SYSTEM STRUCTURE OF APPLICATION OF BI IN M-COMMERCE}

Nowadays, BI is not only software product and tools, but also the overall solution, even a kind of management thought. It reflects a rational ability of management and decisionmaking, an ability of analyzing and processing data and information comprehensively, accurately, timely and thoroughly.

As shown in Figure3, the solution system structure used in M-commerce mainly consists of data source, the ETL process, data storage and data display, in which system flow 
control and metadata management run through the whole system processing link.

1) Data source refers to general term of all kinds of business data (including external data), which can be interviewed extensively. Those data are accumulated from daily operation of E-commerce, such as ERP, SCM, CRM. Though those data are different in storage format and storage location, they are the basis of BI system, and the data source of the entire system.

2) ETL process. According to the rules defined in the database, use the ETL tool to extract data from data of ERP, SCM, CRM and PM, external data, document information and other data. Then the data are conversed and loaded into data warehouse according to corresponding storage structure.

3) The data storage layer mainly contains a central data warehouse and data mart. The central data warehouse corresponds to the whole information view of E-commerce enterprise, which reflects the common requirement of decision information in enterprises. The data mart is designed for departments to support decision-making. The data model and organization are more deserved to information need of a department. In this layer, data from data source will be loaded into central data warehouse and be put into DM after classification, or data from Data Market (DM) will be deposited into Multi-dimension Database (MDD).

4) In this data layer, BI covers many roles, show the too set and users' need. BI can supply users with many access modes, such as periodic report, hoc queries, OLAP, data mining, leadership information system. Users can access the required data to obtain the necessary information in remote or local by wireless terminal device, browser or other frontend tools. For example, product managers can obtain preference and consumption behavior of consumers, financial managers can grasp the cost of consumers and get the interest of mining customers. [10]

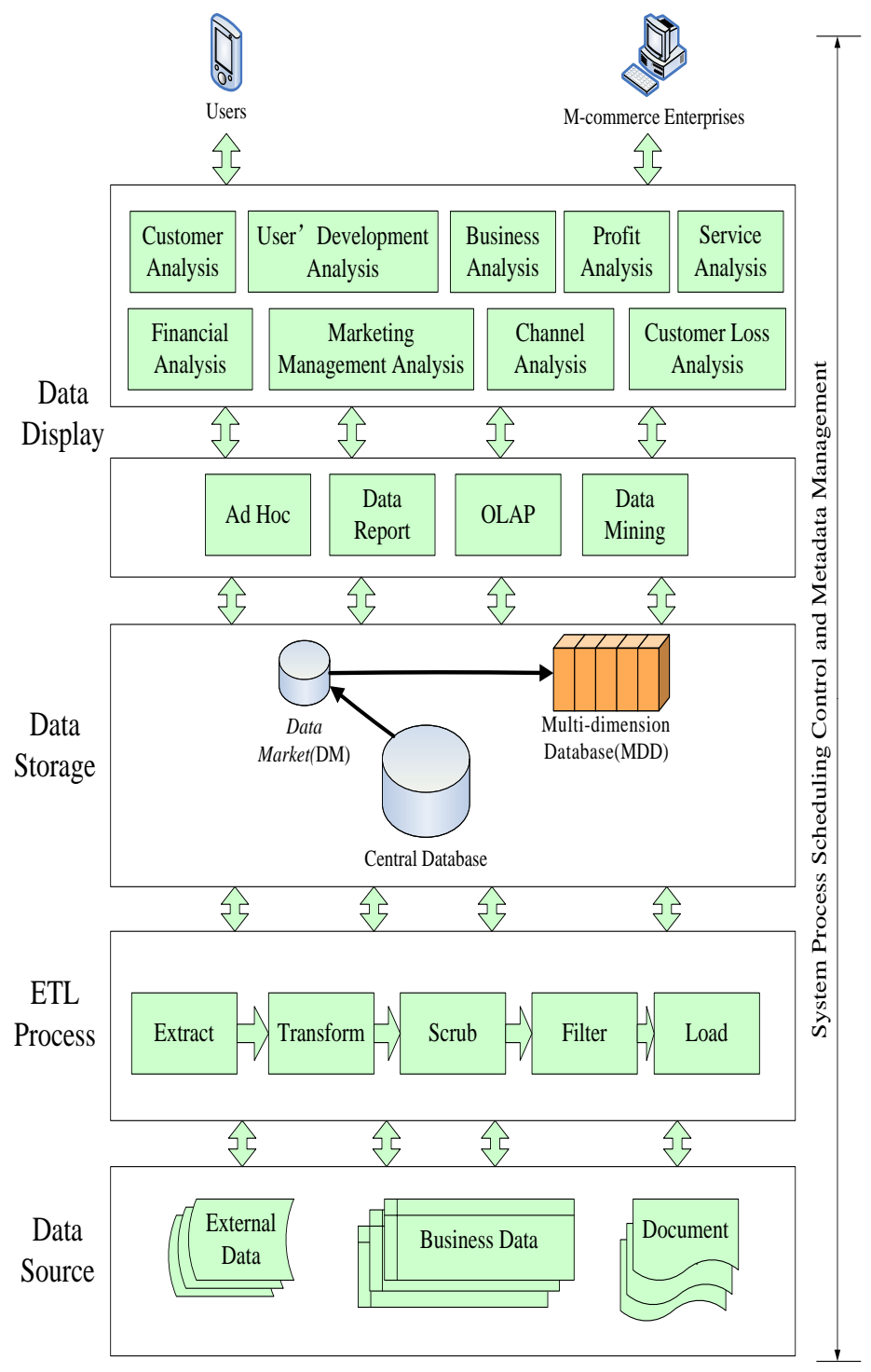

Figure 3. The Solution System Structure of Application of BI in Mcommerce

\section{THE IMPORTANCE OF BUSINESS INTELLIGENCE IN M- COMMERCE}

1) If mass data in M-commerce are dealt with traditional tools and methods of data analysis, it will waste a large amount of manpower, material and financial resources. BI can treat enterprises' internal and external information rapidly by using data warehouse, OLAP, data mining technology, which can effectively shorten the distance between customers and M-commerce enterprises. At the same time, BI can process data in time and sum up effective decision, which enhance business efficiency and save cost for enterprises. 


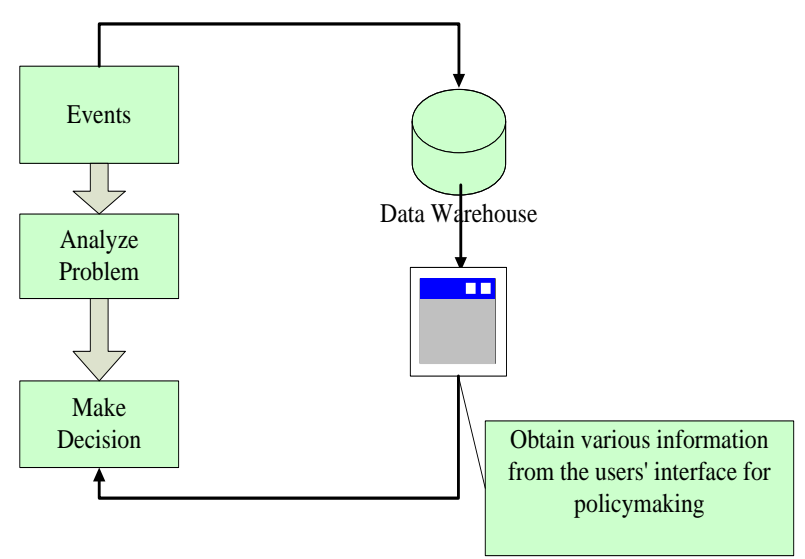

Figure 4. Decision Model in BI Environment

2) BI can help business decision-makers, managers and employees get reliable, personalized operation and performance information timely, grasp their own operation condition and driving force on macro, pierce the effect of M-commerce on business.

3) BI can describe and classify users' behavior characteristics all-round and multi-dimensionally. Then according to the characteristics of users stocked, track customers, do personalized marketing, and tap more potential customers to promote the quantity of users greatly.

4) According to different types of wireless terminal (mobile phone, PDA, tablet PC) and limited sizes of screen, BI can analyze users' possible behavior, provide individualized information customization, push, and service to promote users' experience.

5) Mobile business intelligence possesses good interactive function. Employees can get required information conveniently and quickly from any one of mobile device, even can change data, and process business.

6) In the interior of M-commerce enterprises, it can quantify enterprises and employees' performance, encourage and guide the enthusiasm of the staff, promote innovation to enhance the competitiveness of enterprises.

7) Some historical data of M-commerce enterprises are not perfect and standardized, structured and unstructured data coexist, and data island phenomenon exists. Intelligence business will provide a unified data interface, integrate data into unified data warehouse according to business analysis, to make sure the data be shared and the information comprehensive, accurate, consistent.
8) Employees of M-commerce can make personalized characteristic business report through analysis template defined by intelligence business system and flexible analysis tools, which not only meet the need of business analysis, but also greatly improve work enthusiasm of practitioners.

9) In circulation of M-commerce, BI system demonstrates commodity for customers quickly through wireless network.

\section{CONCLUSION}

The paper mainly discusses the application and effect of $\mathrm{BI}$ in M-commerce, shows the problems that M-commerce enterprises are facing, and put forwards solutions. How to get the information needed in marketing decision-making rapidly from mass data needs future research. The application of BI in M-commerce plays an important role in improving the core competitiveness of enterprises.

\section{ACKNOWLEDGMENT}

This work is supported by 20122BAB211032, JXJG-1113-19 and JC1312.

\section{REFERENCES}

[1] Wikipedia.Business Intelligence[EB/OL], http://en.wikipedia.org/wiki/Business_Intelligence.

[2] Chen Jinbao,"Study of Business Intelligence in E-commerce Application",Beijing University of Posts and Telecommunications, 2008 .

[3] Charles P.Seeley and Thomas H. Davenport,"KM MEETS BUSINESS INTELLIGENCE: Merging knowledge and information at Intel",Knowledge Management Review, Vol.8 No.6,pp.10-15,2006.

[4] William H. Inmon, Building the Data Warehouse,Wiley,2005.

[5] Jiawei Han and Mieheline Kamber,Data Mining:Technique and Concepts,Morgan Kaufmann Publishers,2001.

[6] Zhu J H, Hong J and Hughes J G,"PageCluster: Mining Conceptual Link Hierarchies from Web Log Files for Adaptive Web Site Navigation",ACM Transactions on Internet Technology, Vol.4 No.2,pp.185-208,2004.

[7] Cooley R,Mobasher B and Srivastava J, "Data PreParation for mining world wide web browsing Patterns",Knowledge and Information Systems, Vol.1 No.1,pp.5-32,2005.

[8] Raymond Chi-Wing Wong and Ada Wai-Chee Fu,"ISM:Item Selection for Marketing with Cross-Selling Considerations",Proceedings of The Eighth Pacific-Asia Conference on Knowledge Discovery and Data Mining(PAKDD), vol.3056,pp.431-440,2004.

[9] J.Ben Schafer,JosePh A.Konstan and John Riedl,"E-Commerce commendation Applications",Data Mining and Knowledge Discovery, Vol.5,pp.115-153,2001.

[10] Pui-Munlee,"Behavioral model of online Purchasers in E-Commerce environment”,Electronic Commerce Research, No.2,pp.75-85,2002. 